\title{
The Ecological Niche of bat Viruses Closely Related to SARS-CoV-2, as Inferred from Phylogeographic Analyses of Rhinolophus Species
}

Alexandre HASSANIN ( $\sim$ alexandre.hassanin@mnhn.fr)

Sorbonne University

Vuong Tan Tu

Vietnam Academy of Science and Technology

Manon Curaudeau

Sorbonne University

Gabor Csorba

Hungarian Natural History Museum

\section{Research Article}

Keywords: coronavirus, horseshoe bats, reservoir hosts, Indochina, China, immunity

Posted Date: April 26th, 2021

DOI: https://doi.org/10.21203/rs.3.rs-418434/v1

License: (9) This work is licensed under a Creative Commons Attribution 4.0 International License.

Read Full License

Version of Record: A version of this preprint was published at Scientific Reports on July 12th, 2021. See the published version at https://doi.org/10.1038/s41598-021-93738-z. 
The ecological niche of bat viruses closely related to SARS-CoV-2, as inferred from 1 phylogeographic analyses of $\boldsymbol{R h i n o l o p h u s ~ s p e c i e s ~} 2$

Alexandre Hassanin ${ }^{1}{ }^{*}$, Vuong Tan $\mathrm{Tu}^{2^{\circ}}$, Manon Curaudeau ${ }^{3}$, and Gabor Csorba ${ }^{4}$

${ }^{1}$ Institut de Systématique, Évolution, Biodiversité (ISYEB), Sorbonne Université, MNHN, CNRS, 6 EPHE, UA, Paris; alexandre.hassanin@mnhn.fr $\quad 7$

${ }^{2}$ Institute of Ecology and Biological Resources, Vietnam Academy of Science and Technology, 8

No. 18, Hoang Quoc Viet Road, Cau Giay District, Hanoi, Vietnam; tuvuongtan@gmail.com 9

${ }^{3}$ Institut de Systématique, Évolution, Biodiversité (ISYEB), Sorbonne Université, MNHN, CNRS, 10

EPHE, UA, Paris; manon.curaudeau1@mnhn.fr $\quad 11$

${ }^{4}$ Department of Zoology, Hungarian Natural History Museum, Baross u. 13, Budapest H-1088, 12

Hungary; csorba.gabor@nhmus.hu

$\begin{array}{ll}{ }^{\circ} \text { co-first authors } & 14\end{array}$

* correspondence: alexandre.hassanin@mnhn.fr; Tel.: +33140795693 15 
$\begin{array}{ll}\text { Abstract } & 17\end{array}$

To date, viruses closely related to SARS-CoV-2 have been reported in four bat species: 19 Rhinolophus acuminatus, Rhinolophus affinis, Rhinolophus malayanus, and Rhinolophus shameli. 20 Here, we analysed 343 sequences of the mitochondrial cytochrome c oxidase subunit 1 gene $(C O 1) 21$ from georeferenced bats of the four Rhinolophus species identified as reservoirs of viruses closely 22 related to SARS-CoV-2. Haplotype networks were constructed in order to investigate patterns of 23 genetic diversity among bat populations of Southeast Asia and China. No strong geographic structure was found for the four Rhinolophus species, suggesting high dispersal capacity. The ecological niche of bat viruses closely related to SARS-CoV-2 was predicted using the four 26 localities in which bat viruses were recently discovered and the localities where bats showed the 27 same $C O 1$ haplotypes than virus-positive bats. The ecological niche of bat viruses related to SARS- 28 CoV was deduced from the localities where bat viruses were previously detected. The results show 29 that the ecological niche of bat viruses related to SARS-CoV2 includes several regions of mainland Southeast Asia whereas that of bat viruses related to SARS-CoV is mainly restricted to China. In 31 agreement with these results, human populations in Laos, Vietnam, Cambodia, and Thailand appear 32 to be much less affected by the Covid-19 pandemic than other countries of Southeast Asia. In the 33 climatic transitional zone between the two ecological niches (southern Yunnan, northern Laos, 34 northern Vietnam), genomic recombination between highly divergent viruses is more likely to occur. Since recombinant viruses can threaten the benefit of vaccination campaigns, these regions 36 should be under surveillance.

Keywords: coronavirus; horseshoe bats; reservoir hosts; Indochina; China; immunity. 


\section{Introduction}

The Severe Acute Respiratory Syndrome coronavirus 2 (SARS-CoV-2) emerged in December

2019 in Wuhan (China) [1]. After 16 months, the coronavirus disease 2019 (Covid-19) pandemic

has affected more than 137 million of people around the world, claiming over 2.95 million lives

[2]. The origin of SARS-CoV-2 remains enigmatic and many hypotheses have been advanced to

Within the family Coronaviridae, the subgenus Sarbecovirus includes two human viruses, SARS-

CoV-2 and SARS-CoV (which was responsible for the SARS epidemic in 2002-2004) [4]. The

phylogenies have shown that they belong to two divergent lineages $[1,5-7]$, which we refer to

herein as SARS-CoV related coronaviruses ( $\mathrm{SCoVrCs})$ and SARS-CoV-2 related coronaviruses

(SCoV2rCs). Most SCoVrCs were discovered in bats collected in China after the SARS epidemic,

and the great majority were found in horseshoe bat species of the genus Rhinolophus (family

from a $R$. affinis bat collected in Yunnan in 2013 [1]; the RmYN02 virus was found in a $R$. 56 malayanus bat sampled in Yunnan in 2019 [5]; two variants of the same virus RshSTT200 (other

[6]; and five variants of the same virus RacCS203 (other variants: RacCS224, RacCS253, 
discovery of two divergent sarbecovirus genomes in horseshoe bat species collected out of Asia:

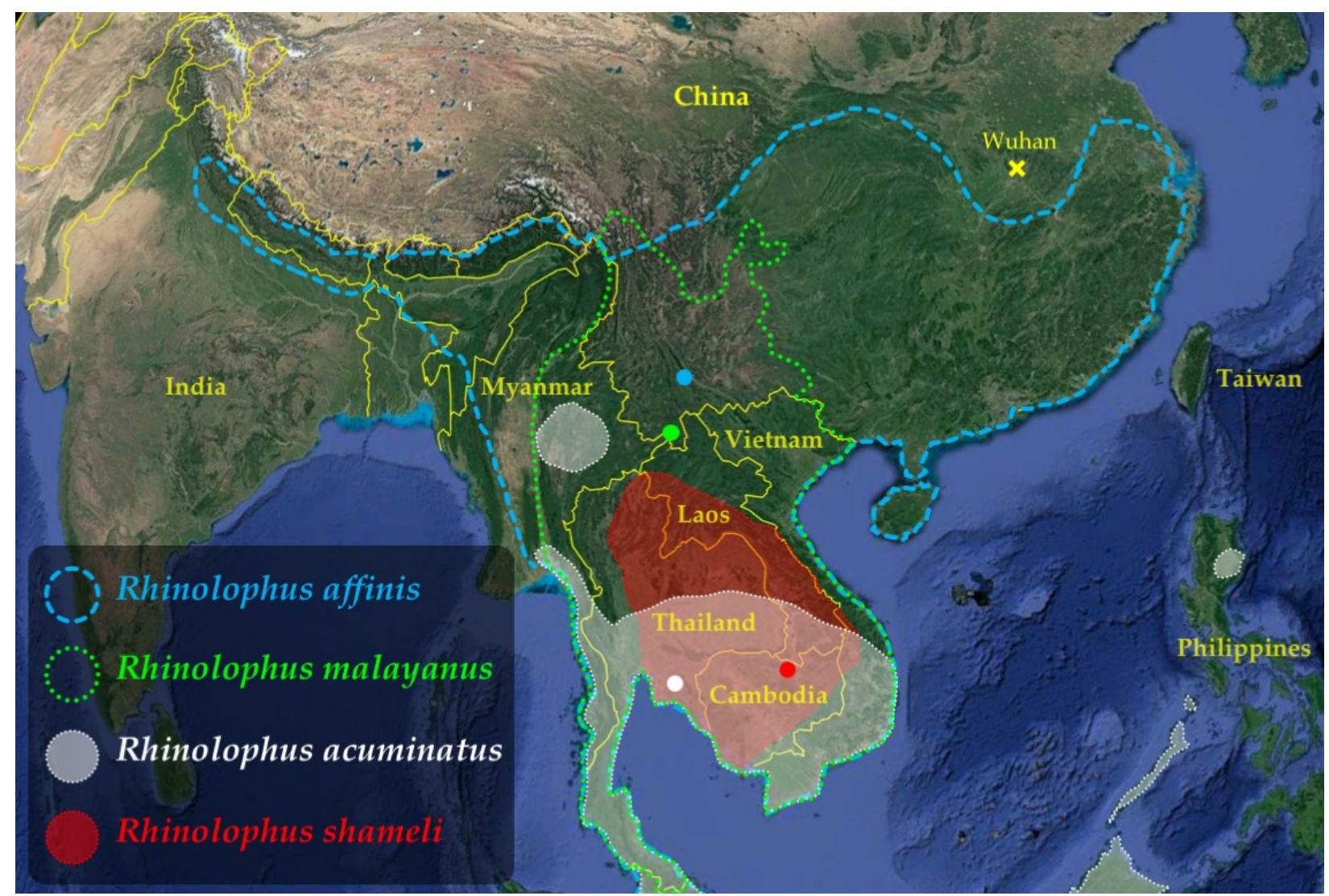

Figure 1. Geographic distribution of the four Rhinolophus species found positive for viruses closely related to SARS-CoV-2 in southern China and Southeast Asia. Map from Google Earth US Dept of State Geographer (C) 2020 Google - Image Landsat / Copernicus - Data SIO, NOAA, U.S. Navy, NGA, GEBCO. For each of the four Rhinolophus species, the geographic distribution was extracted from the IUCN website [11]. The coloured dots show the four geographic locations where bats found positive for SCoV2rCs were collected.

Since SCoV2rCs have been circulating in horseshoe bats for many decades [12], it is important to 
bat populations. The results of these analyses were used to select specific location coordinates to

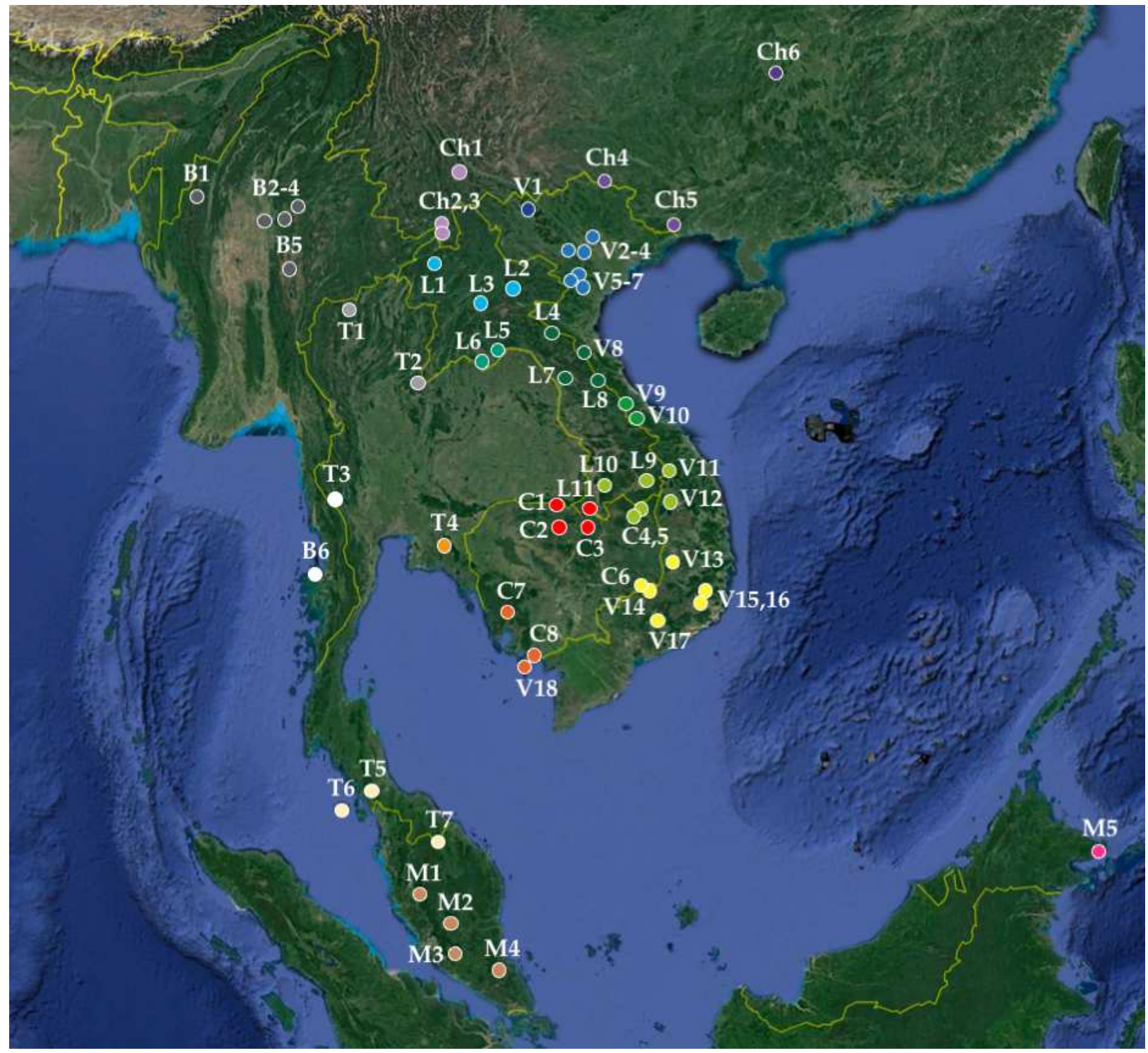

Figure 2. Geographic localities analysed in this study. The codes used for the countries are the 
Until now, SCoV2rCs have been found in four bat species of the genus Rhinolophus: R. 97 acuminatus, $R$. affinis, $R$. malayanus, and $R$. shameli. The haplotype networks constructed using

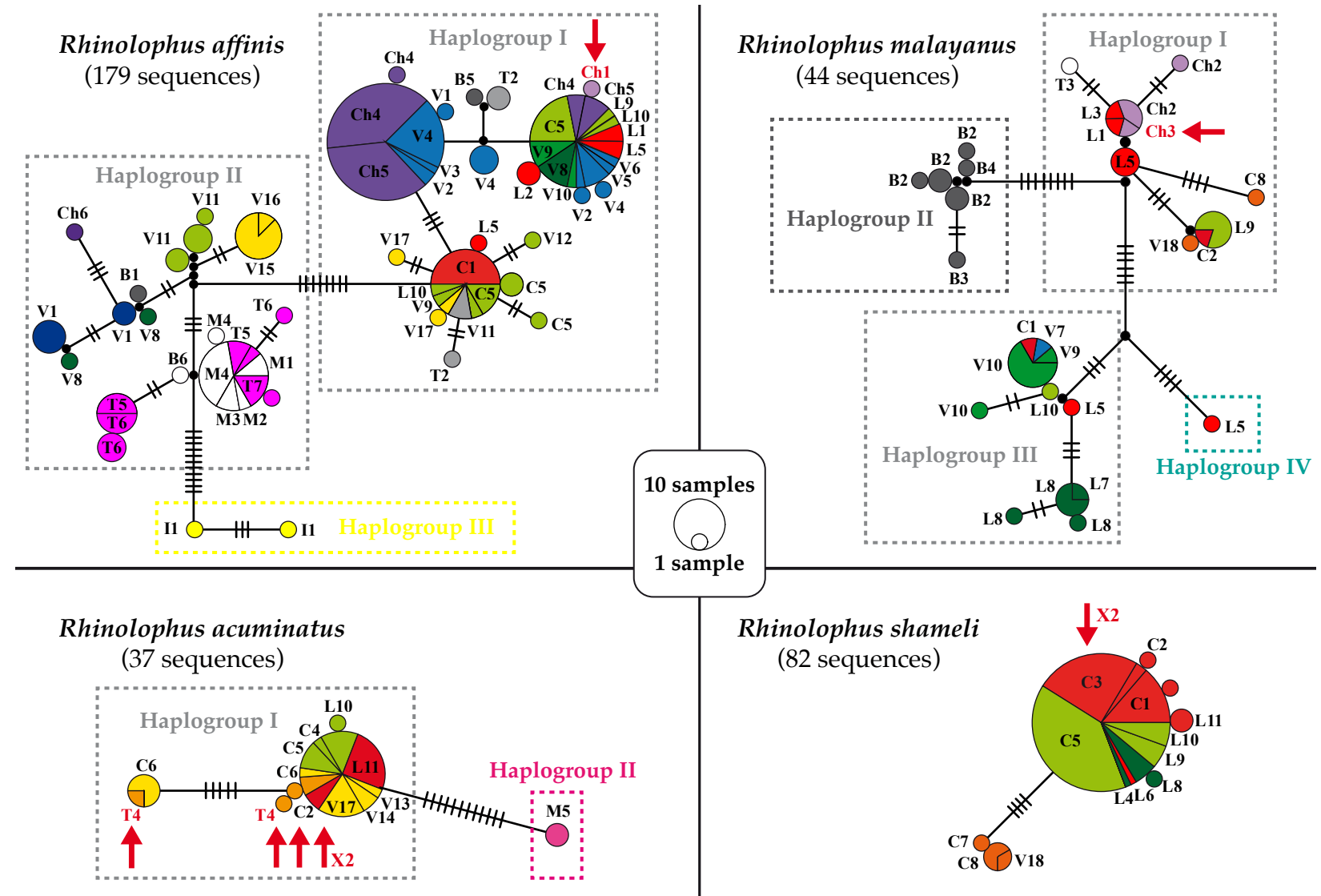

Figure 3. Haplotype networks based on CO1 sequences of the four Rhinolophus species found positive for viruses closely related to SARS-CoV-2 (SCoV2rCs). The networks were constructed with the median joining method available in PopART 1.5 [13]. The codes used for the countries are the following: B (Myanmar), C (Cambodia), Ch (China), I (Indonesia), L (Laos), M (Malaysia), $\mathrm{T}$ (Thailand), and V (Vietnam). Colours indicate the geographic origin of haplotypes according to Fig. 2 (see online supplementary table S1). The circles indicate haplotypes separated by at least one mutation. The black lines on the branches show the number of mutations $\geq 2$. Black circles represent missing haplotypes. Circle size is proportional to the number of haplotypes. Haplogroups separated by more than seven mutations (pairwise nucleotide distances $>1 \%$ ) are highlighted by dotted lines. The red arrows show the positions of the nine bats found positive for SCoV2rCs. 
SARS-CoV-2 (91.8\% of genome identity), named RacCS203, was detected in five $R$. acuminatus

bats caught in eastern Thailand in June 2020 [6], the genetic pattern obtained for this species

mainland Southeast Asia. In contrast, R. acuminatus bats collected in Borneo (M5) showed a

Sea between mainland Southeast Asia and Borneo constitutes a barrier to gene flow. Isolated

populations of $R$. acuminatus described in northern Myanmar, Indonesia (Java and Sumatra) and

The network of $R$. shameli shows a typical star-like pattern, the most common haplotype (named Rsh1 in online supplementary table S1) being detected in northern Cambodia and Laos. Since a virus related to SARS-CoV-2 (93.1\% of genome identity), named RshSTT200, was recently discovered in two $R$. shameli bats collected in northern Cambodia in December 2010 [7], the genetic pattern obtained for this species suggests that viruses closely related to RshSTT200 may have circulated, at least in the zone between northern Cambodia and central Laos. The bats sampled south to the Tonle Sap lake ( $\mathrm{n}=4$; southern Cambodia and Vietnamese island of Phu Quoc) were found to be genetically isolated from northern populations (four mutations). However, further sampling in the south is required to confirm this result, as it may reveal $C O 1$ sequences identical

For the two species distributed in both China and Southeast Asia, i.e. $R$. affinis and R. malayanus, the genetic patterns are more complex with different haplogroups showing more than $1 \%$ of nucleotide divergence. In the network of $R$. affinis, there are three major haplogroups (named I, II and III in Fig. 3) separated by a minimum of seven mutations. The results are therefore in agreement with those previously published using $C O 1$ and D-loop mitochondrial sequences [15]. The COI haplotypes detected in the localities sampled in southern China (ch1, ch4, ch5) are distantly related to the single haplotype available for central China (ch6), but they are also found in Laos, northern and central Vietnam, northern Thailand and northeastern Myanmar. This result suggests recent 
gene flow between populations from southern Yunnan and those from northern mainland Southeast

Asia. Since a virus related to SARS-CoV-2 (96.2\% of genome identity), named RaTG13, was

detected in one $R$. affinis bat captured in southern Yunnan in 2013 [1], the genetic pattern obtained

for this species suggests that viruses closely related to RaTG13 may have circulated in the zone

In the network of $R$. malayanus, there are four major haplogroups (named I, II, III and IV in Fig.

3) separated by a minimum of seven mutations. The COI haplotypes detected in the localities

sampled in southern China (ch2 and ch3) were also found in northern Laos (L1 and L3), suggesting

recent gene flow between populations from these two countries. Since a virus related to SARS-

CoV-2 (93.7\% of genome identity), named RmYN02, was recently isolated from one $R$. malayanus

bat collected in southern Yunnan in June 2019 [5], the genetic pattern obtained for this species suggests that viruses closely related to RmYN02 may have circulated, at least between southern

\section{Two different ecological niches for bat viruses related to either SARS-CoV or SARS-CoV-2}

Sarbecoviruses have been already detected in a wide diversity of horseshoe bat species collected

in Asia, Africa and Europe [5-10]. Therefore, there is no doubt that Rhinolophus species constitute

the natural reservoir host of all sarbecoviruses [3,8]. The genus Rhinolophus currently includes between 92 [11] and 109 [16] insectivorous species that inhabit temperate and tropical regions of 
which sarbecoviruses were detected in previous studies $[1,5-9 ; 17]$ are cave species that form small

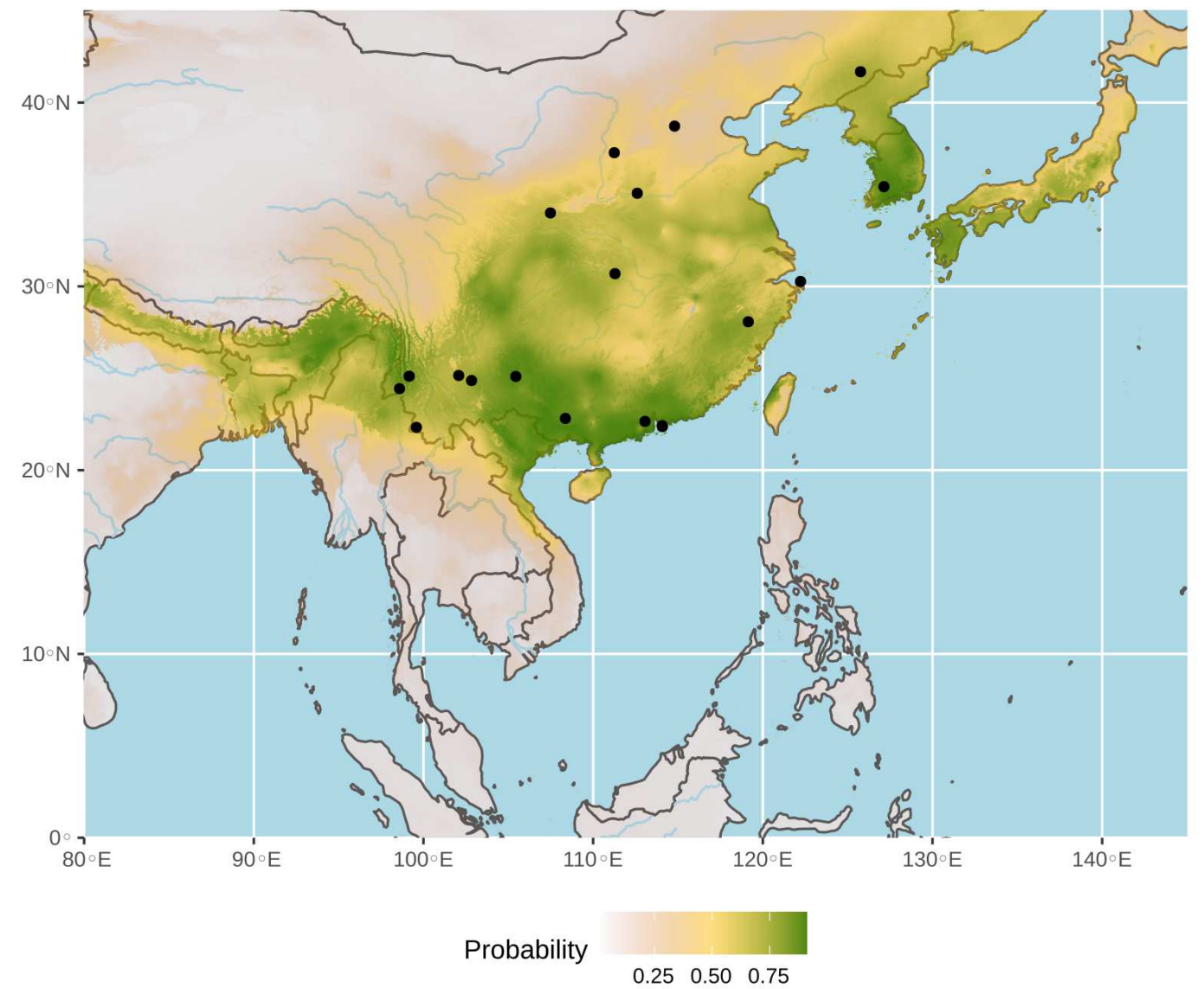

Figure 4. Ecological niche of bat viruses related to SARS-CoV (SCoVrCs). The geographic distribution of suitable environments was predicted using the Maxent algorithm in ENMTools (see Methods for details). AUC $=0.81$. Black circles indicate localities used to build the distribution model (see geographic coordinates in online supplementary table S2).

In China, many SCoVrCs were previously detected in several horseshoe bat species, including been shown that they circulate not only among conspecific bats from the same colony, but also between bat species inhabiting the same caves $[17,20,21]$. The ecological niche predicted for bat SCoVrCs using a data set of 19 points (see online supplementary table S2) is shown in Fig. 4. The AUC was 0.81 . The value was $>95 \%$ CI null-model's AUCs (0.68), indicating that the model performs significantly better than a random model (see online supplementary Fig. S1). The highest 
Bangladesh, northeastern India, northern Myanmar, northern Vietnam, most regions of China south

In Southeast Asia and southern China, SCoV2rCs have currently been found in four Rhinolophus species (R. acuminatus, $R$. affinis, R. malayanus and R. shameli) [1,6-8], but the greatest diversity of horseshoe bat species in mainland Southeast Asia (between 28 and 36 species) $[11,16]$ suggests that many sarbecoviruses will be discovered soon. Despite the limited data currently available on SCoV2rCs, several arguments support that bat intraspecific and interspecific transmissions also occur with SCoV2rCs. Firslty, recent genomic studies have revealed that SCoV2rCs circulate and evolve among horseshoe bats of the same colony, as five very similar genomes (nucleotide distances between $0.03 \%$ and $0.10 \%$ ) were sequenced from five $R$. acuminatus bats collected from the same colony in eastern Thailand [6], and as two genomes differing at only three nucleotide positions $($ distance $=0.01 \%$ ) were sequenced from two $R$. shameli bats collected at the same cave entrance on the same night [7]. Secondly, the discovery of four viruses closely related to SARSCoV-2 (between 96.2 and $91.8 \%$ of genome identity) in four different species of Rhinolophus is a strong evidence that interspecific transmission occurred several times in the past. As detailed in online supplementary Table S1, these species were collected together in several localities of 

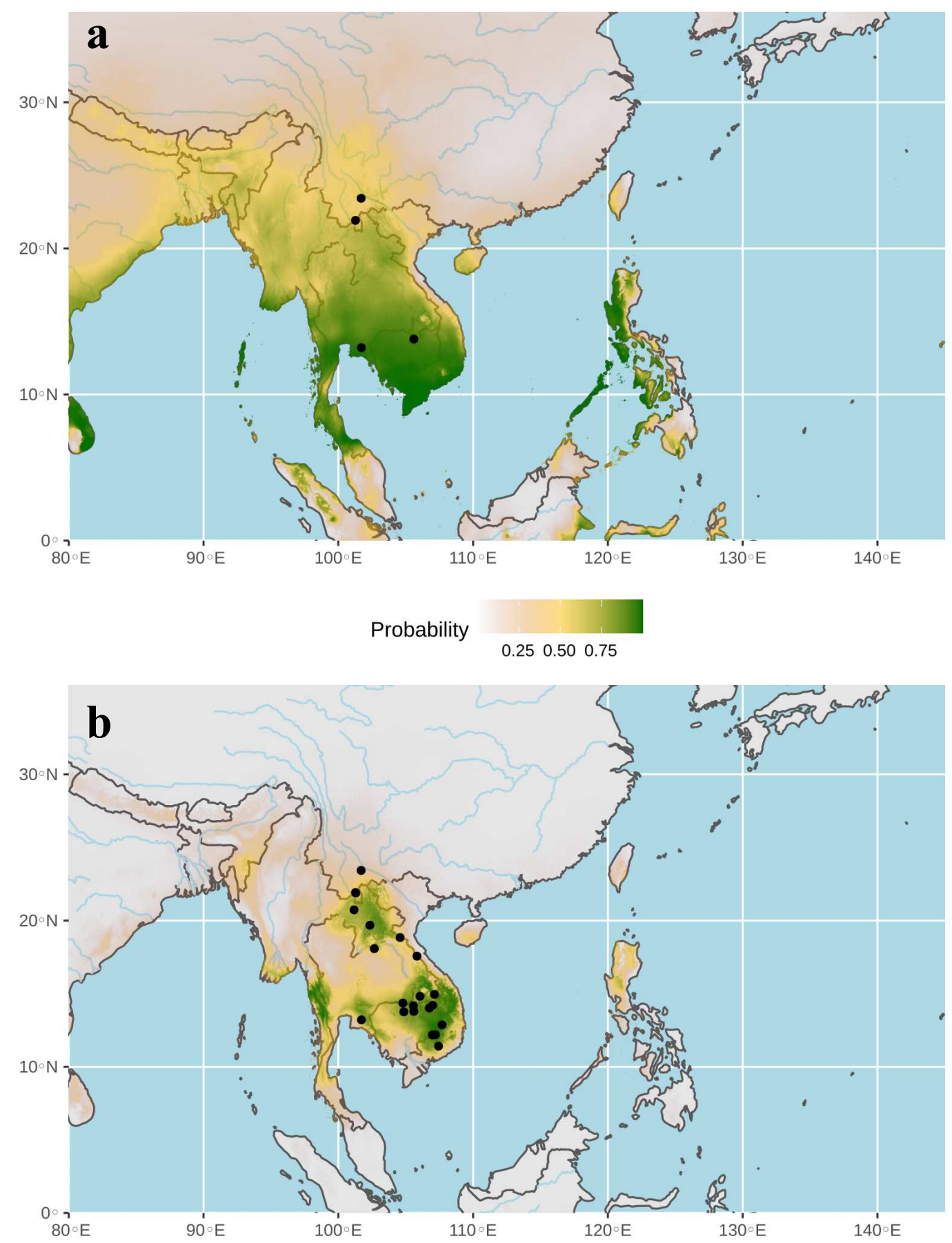

Figure 5. Ecological niches of bat viruses closely related to SARS-CoV-2 (SCoV2rCs) predicted using 4 points (a) $(\mathrm{AUC}=0.58)$ and 21 points $(\mathrm{b})(\mathrm{AUC}=0.96)$. The geographic distributions of suitable environments were predicted using the Maxent algorithm in ENMTools (see Methods for details). Black circles indicate localities used to build the distribution model (see geographic coordinates in online supplementary table S1).

The ecological niche of bat SCoV2rCs was firstly predicted using the four localities where bat 
AUC was only 0.58 , and the value was $<95 \%$ CI null-model's AUCs (0.74), indicating that the model was not statically supported at a significance level of 0.05 (see on line supplementary Fig. S2). As expected, these preliminary results confirmed that more than four records are needed to increase the accuracy of the distribution model [22]. For that reason, we used a genetic approach to determine geographic localities where bat SCoV2rCs are more likely to be found. The CO1 sequences of the nine bats in which a $\mathrm{SCoV} 2 \mathrm{rC}$ was detected are shown by red arrows in Fig. 3.221 For $R$. affinis, the COl haplotype sequenced for the bat found positive for a SCoV2rC in southern Yunnan (site named Ch1 in Fig. 2 and 3) was not found in other sampled localities. For the three other bat species found positive for $\mathrm{SCoV} 2 \mathrm{rCs}$, identical $\mathrm{CO} 1$ sequences were detected in bats from 17 other geographic localities (see online supplementary table $\mathrm{S} 1$ ). For $R$. acuminatus, the four 225 CO1 haplotypes sequenced for the bats found positive for SCoV2rCs in eastern Thailand (site named T4 in Fig. 2 and 3) were also found in four localities in Cambodia (C2, C4, C5, and C6), 227 two localities in southern Laos (L10 and L11), and three localities in southern Vietnam (V13, V14, 228 and V17). The results indicate high connectivity among $R$. acuminatus populations from eastern 229 Thailand, Cambodia, southern Laos and southern Vietnam. For R. malayanus, the CO1 haplotype 230 sequenced for the bat found positive for a SCoV2rC in southern Yunnan (site named Ch3 in Fig. 2 and 3) was also found in another locality in southern Yunnan (Ch2) and two localities in northern Laos (L1 and L3). The results indicate high connectivity among $R$. malayanus populations from southern China and northern Laos. For $R$. shameli, the single $C O 1$ haplotype sequenced for the two bats found positive for SCoV2rCs in northern Cambodia (site named C3 in Fig. 2 and 3) was also found in three other localities in Cambodia (C1, C2, and C5) and five localities in Laos (L4, L6, L8, L9, and L10). The results indicate high connectivity among $R$. shameli populations from Cambodia and Laos. Based on these genetic data, the ecological niche of bat SCoV2rCs was predicted using 21 records corresponding to the four localities where bat viruses were previously detected [1,6-8] and the 17 localities where bats showed the same COI haplotype than virus- 
0.96. The value was $>95 \%$ CI null-model's AUCs (0.81), indicating that the model performs significantly better than a random model (see online supplementary Fig. S3). The areas showing the highest probabilities of occurrence (highlighted in green in Fig. 5b) include southern Yunnan, northern and southern Laos, northwestern and southern Vietnam, northeastern and southwestern Cambodia, eastern, northern and western Thailand, and southern Myanmar.

Our results show that bat $\mathrm{SCoVrCs}$ and $\mathrm{SCoV} 2 \mathrm{rCs}$ have different evological niches: that of SCoVrCs covers mainly China and several adjacent countries and extends to latitudes between $18^{\circ}$ and $43^{\circ} \mathrm{N}$, whereas that of SCoV2rCs covers northern mainland Southeast Asia and extends to latitudes between $10^{\circ}$ and $24^{\circ} \mathrm{N}$. Most Rhinolophus species involved in the ecological niche of SCoVrCs have to hibernate in winter when insect populations become significantly less abundant. 252 This is not the case for most Rhinolophus species involved in the ecological niche of SCoVrC2s. Since this ecological difference may be crucial for the dynamics of viral transmission among bat populations, it needs to be further studied through comparative field surveys in different regions of

The ecological niches of SCoVrCs and SCoV2rCs slightly overlap in the zone including southern Yunnan, northern Laos, and northern Vietnam (Fig. 4 and Fig. 5b). This zone corresponds to the northern edge of tropical monsoon climate [23]. Highly divergent sarbecoviruses of the two main lineages $\mathrm{SCoVrCs}$ and $\mathrm{SCoV} 2 \mathrm{rCs}$ are expected to be found in sympatry in this area. This is confirmed by the discovery of both SCoVrCs and SCoV2rCs in horseshoe bats collected in southern Yunnan [1,6,21]. Collectively, these data suggest that genomic recombination between viruses of the two divergent lineages are more likely to occur in bats roosting, at least seasonally, 

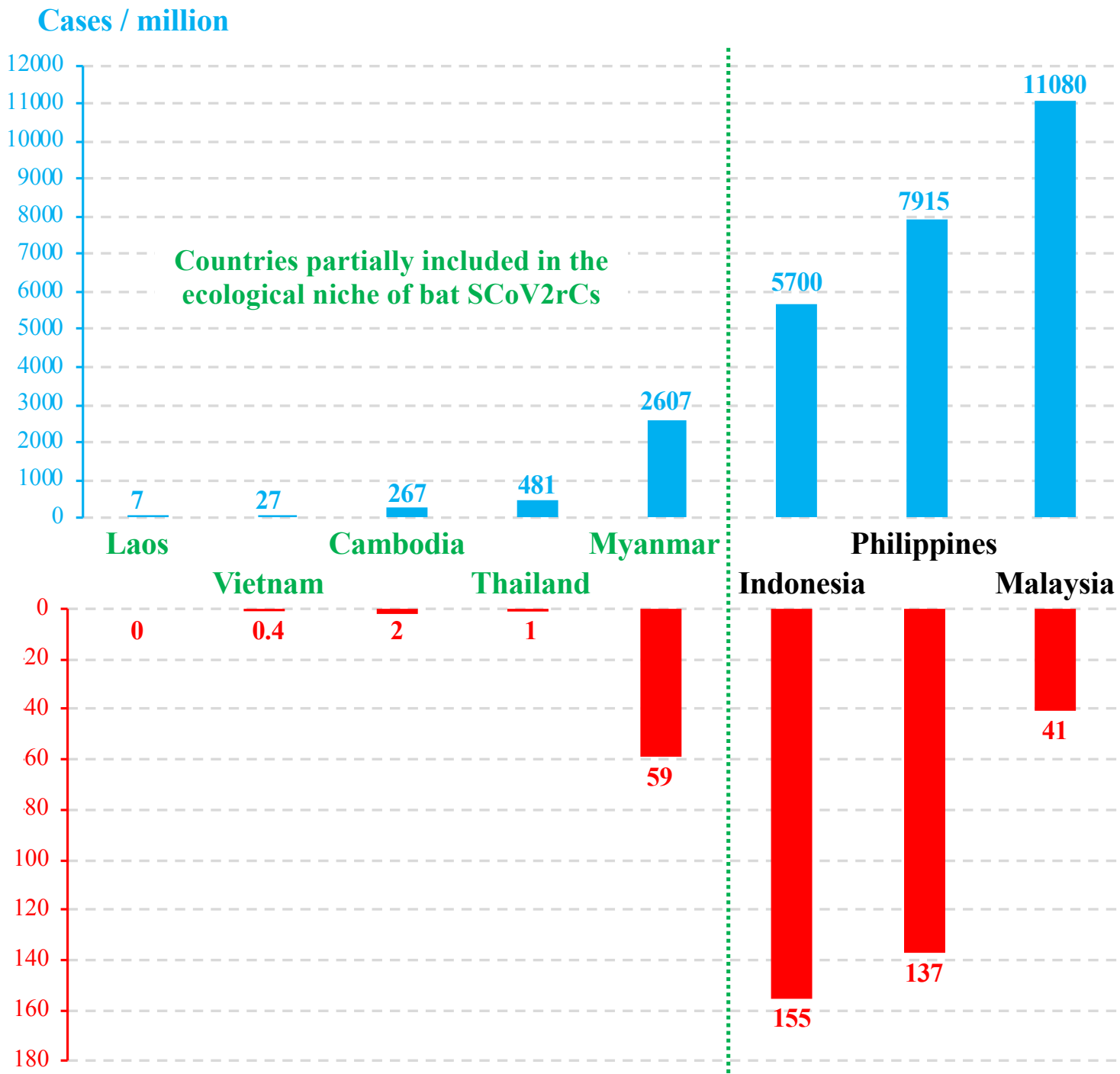

Deaths / million

Figure 6. Number of Covid-19 patients per million inhabitants (in blue) and deaths per 270 million inhabitants (in red) for the different countries of Southeast Asia. Data extracted from the Worldometers website [2] on April 12, 2021.

Chinese researchers have actively sought sarbecoviruses in all Chinese provinces after the 20022004 SARS outbreak. They found many bat SCoVrCs $[16,20,21]$ but only two SCoV2rCs $[1,5]$ Asia. The ecological niches predicted herein for bat sarbecoviruses suggest that SCoVrCs are 
Southeast Asia, and that different species of bats have exchanged these viruses in the caves they

inhabit.

The data available on human cases and deaths caused by the Covid-19 pandemic [2] indirectly support the hypothesis that the cradle of diversification of bat SCoV2rCs is mainland Southeast Asia, and in particular the areas highlighted in green in Fig. 5b. Indeed, human populations in Cambodia, Laos, Thailand, and Vietnam appear to be much less affected by the Covid-19 pandemic than other countries of the region, such as Indonesia, Malaysia, Myanmar, and the Philippines (Fig. particular rural populations living in contact with wild animals for several generations, have a better immunity against SCoV2rCs because they have been regularly contaminated by bats and/or infected secondary hosts such as pangolins.

\section{Pangolins contaminated by bats in Southeast Asia}

Apart from bats, the Sunda pangolin (Manis javanica) and Chinese pangolin (Manis pentadactyla)

are the only wild animals in which viruses related to SARS-CoV-2 have been found so far.

However, these discoveries were made in a rather special context, that of pangolin trafficking. Several sick pangolins were seized by Chinese customs in Yunnan province in 2017 (unpublished data), in Guangxi province in 2017-2018 [24] and in Guangdong province in 2019 [25]. Even if the viruses sequenced in pangolins are not that close to SARS-CoV-2 (one was $85 \%$ identical and the other 90\%), they indicate that at least two sarbecoviruses could have been imported into China well before the emergence of Covid-19 epidemic. Indeed, it has been shown that Sunda pangolins collected from different Southeast Asian regions have contaminated each other while in captivity on Chinese territory [3]. The question remained on how the Sunda pangolins became infected initially. Could it have been in their natural Southeast Asian environment, before being captured? The discovery of two new viruses close to SARS-CoV-2 in bats from Cambodia and Thailand $[7,8]$ 
forests of Southeast Asia, possibly in caves, tree hollows or burrows. Further substantiating this hypothesis, the geographic distribution of Manis javanica [26] overlaps the ecological niche here predicted for bat SCoV2rCs (Fig. 5), and SARS-CoV-2 neutralizing antibodies have been recently detected in a Sunda pangolin collected in eastern Thailand [6]. Collectively, these data strengthen the hypothesis that pangolin trafficking is responsible for multiple exports of viruses related to

\section{Methods}

\section{DNA extraction and sequencing}

One hundred and forty-four tissue samples of morphologically identified bats of $R$. acuminatus (n $=10), R$. affinis $(\mathrm{n}=57), R$. malayanus $(\mathrm{n}=14)$, and $R$. shameli $(\mathrm{n}=63)$ were specially analysed

Total DNA was extracted using QIAGEN DNeasy Tissue Kit (Qiagen, Germany) in accordance

with the manufacturer's instructions. The barcode fragment of the COl gene (657 bp) was

(GE Healthcare, UK) and sequenced using the Sanger method on an ABI 3730 automatic sequencer 
Our sequences were aligned with 199 additional CO1 sequences downloaded from GenBank. Note

that the $\mathrm{CO} 1$ sequences of seven bats found positive for viruses closely related to SARS-CoV-2

$[1,5,6]$ were assembled on Geneious ${ }^{\circledR}$ 10.2.2 (Biomatters Ltd., Auckland, New Zealand) by

Our final CO1 alignments contain 37 sequences for $R$. acuminatus, 44 sequences for $R$. malayanus, weights for all mutations. The 62 localities where bats were sampled are shown in the map of Fig.

For bat SCoVrCs, the ecological niche was inferred using GPS data collected for viruses published

during the last two decades. The list of the 19 available geographic records is provided in online

supplementary table S2. For bat SCoV2rCs, the ecological niche was initially predicted using the

four geographic localities where viruses were previously detected [1,5-7]: two in Yunnan, one in

northern Cambodia, and one in eastern Thailand (data set A). However, the use of only four records

is questionable since Van Proosdij et al. [22] have estimated that a minimum of 13 records is

required to develop accurate distribution models for widespread taxa. For that reason, we used a

genetic approach to increase the number of geographic records. Since the detection of identical 
also selected the 17 geographic records where bats showed the same $\mathrm{CO} 1$ haplotypes than virus-

positive bats (data set B: 21 points; see online supplementary table S1).

For each of the three data sets (bat SCoVrCs; data sets A and B for bat SCoV2rCs), the 19

bioclimatic variables available in the WorldClim database [31] were studied for an area

points for bat SCoVrCs; 4 and 21 points, respectively for the SCoV2rCs data sets A and B) and the

caret $\mathrm{R}$ package [32] was used to determine the least correlated variables $(|\mathrm{r}|<0.7)$ [33]. For bat

$\mathrm{SCoVrCs}$, the following five predictor bioclimatic variables were retained: Bio3 (isothermality),

Bio4 (temperature seasonality), Bio5 (maximum temperature of the warmest month), Bio15

(precipitation seasonality), and Bio18 (precipitation of the warmest quarter). For data set A, the

following seven predictor bioclimatic variables were retained: Bio3, Bio7 (temperature annual

range), Bio10 (mean temperature of the warmest quarter), Bio13 (precipitation of the wettest

month), Bio14 (precipitation of driest month), Bio15, and Bio18. For data set B, the following

seven predictor bioclimatic variables were selected: Bio2 (mean diurnal range), Bio3, Bio7, Bio10,

366

Bio13, Bio15, Bio17 (precipitation of the driest quarter), and Bio18. Ecological niche modelling

chosen for its ability to work with presence-only data sets and to produce results with a low sample

size [35]. The area under the curve (AUC) of the receiver operating characteristic plot was used as

a first measure of model accuracy, a value of 0.5 indicating model accuracy not better than random,

and a value of 1 indicating perfect model fit [36,37]. To test for sampling bias, the distribution 
was tested against the $95 \%$ confidence interval (CI) of the 1000 AUC values of the null-models. If 375 the AUC value is $\geq 95 \%$ CI null-model's AUCs, the model is considered performing significantly 376 better than a random model [37].

References 379

1. Zhou, P. et al. A pneumonia outbreak associated with a new coronavirus of probable bat origin. 380 Nature 579, 270-273; 10.1038/s41586-020-2012-7 (2020). 381

2. COVID-19 Coronavirus pandemic. https://www.worldometers.info/coronavirus/. downloaded 382 on April 12, 2021.

3. Hassanin, A., Grandcolas, P. \& Veron, G. Covid-19: natural or anthropic origin? Mammalia 384 85, 1-7; 10.1515/mammalia-2020-0044 (2021).

4. Walker, P.J. et al. Changes to virus taxonomy and the statutes ratified by the international committee on taxonomy of viruses. Arch Virol. 165, 2737-2748; 10.1007/s00705-020-04752$\mathrm{x}(2020)$

5. Zhou, H. et al. A novel bat coronavirus closely related to SARS-CoV-2 contains natural 389 insertions at the S1/S2 cleavage site of the spike protein. Curr. Biol. 30, 3896; 390 10.1016/j.cub.2020.09.030 (2020).

6. Wacharapluesadee, S. et al. Evidence for SARS-CoV-2 related coronaviruses circulating in 392 bats and pangolins in Southeast Asia. Nat. Commun. 12, 972; 10.1038/s41467-021-21240-1 (2021).

7. Hul, V. et al. A novel SARS-CoV-2 related coronavirus in bats from Cambodia. 395 10.1101/2021.01.26.428212 (submitted).

8. Li, W. et al. Bats are natural reservoirs of SARS-like coronaviruses. Science 310, 676-679; 10.1126/science.1118391 (2005). 
9. Drexler, J.F. et al. Genomic characterization of severe acute respiratory syndrome-related coronavirus in European bats and classification of coronaviruses based on partial RNA- 400 dependent RNA polymerase gene sequences. J. Virol. 84, 11336-11349; 10.1128/JVI.00650- 401 $10(2010) . \quad 402$

10. Tao, Y. \& Tong, S. Complete genome sequence of a severe acute respiratory syndrome-related 403 coronavirus from Kenyan bats. Microbiol. Resour. Announc. 8, e00548-19; 404 10.1128/MRA.00548-19 (2019). 405

11. The IUCN Red List of Threatened Species. Version 2020-3. https://www.iucnredlist.org. 406 $\begin{array}{ll}\text { Downloaded on } 23 \text { February } 2021 . & 407\end{array}$

12. Boni, M.F. et al. Evolutionary origins of the SARS-CoV-2 sarbecovirus lineage responsible 408 for the COVID-19 pandemic. Nat. Microbiol. 5, 1408-1417; 10.1038/s41564-020-0771-4 409 (2020).

13. Leigh, J.W. \& Bryant, D. PopART: Full-feature software for haplotype network construction. Methods Ecol. Evol. 6, 1110-1116; 10.1111/2041-210X.12410 (2015).

14. Thong, V.D., Thanh, H.T., Soisook, P. \& Csorba, G. Rhinolophus acuminatus. The IUCN Red List of Threatened Species e.T19520A21974227; 10.2305/IUCN.UK.2019- 414 3.RLTS.T19520A21974227.en. (2019).

15. Ith, S. et al. Taxonomic implications of geographical variation in Rhinolophus affinis 416 (Chiroptera: Rhinolophidae) in mainland Southeast Asia. Zool. Stud. 54, e31; 10.1186/s40555015-0109-8 (2015).

16. Burgin, C.J., Wilson, D.E., Mittermeier, R.A., Rylands, A.B., Lacher, T.E., Sechrest, W. Illustrated Checklist of the Mammals of the World. Vol. 2. Lynx Edicions, Barcelona (2020).

17. Fan, Y., Zhao, K., Shi, Z. L. \& Zhou, P. Bat coronaviruses in China. Viruses 11, 210; 421 $10.3390 / \mathrm{v} 11030210(2019)$.

18. Francis, C. Field Guide to the Mammals of South-east Asia. Bloomsbury, London, UK. (2019). 
19. Smith, A.T. \& Xie, Y. A Guide to the Mammals of China. Princeton University Press, 424 Princeton, New Jersey (2008).

20. Han, Y. et al. Identification of diverse bat alphacoronaviruses and betacoronaviruses in China 426 provides new insights into the evolution and origin of coronavirus-related diseases. Front. 427 Microbiol. 10, 1900; 10.3389/fmicb.2019.01900 (2019).

21. $\mathrm{Hu}, \mathrm{D}$. et al. Genomic characterization and infectivity of a novel SARS-like coronavirus in 429 Chinese bats. Emerg. Microbes Infect., 7, 154; 10.1038/s41426-018-0155-5 (2018).

22. van Proosdij, A.S.J., Sosef, M.S.M., Wieringa, J.J. \& Raes N. Minimum required number of specimen records to develop accurate species distribution models. Ecography 39, 542-552; 10.5061/dryad.8sb8v (2016).

23. Song, Y., Achberger, C. \& Linderholm, H.W. Rain-season trends in precipitation and their effect in different climate regions of China during 1961-2008. Environ. Res. Lett. 6, 034025; 435 10.1088/1748-9326/6/3/034025 (2011).

24. Lam, T.T. et al. Identifying SARS-CoV-2-related coronaviruses in Malayan pangolins. Nature 583, 282-285; 10.1038/s41586-020-2169-0 (2020).

25. Liu, P., Chen, W. \& Chen, J.P. Viral metagenomics revealed Sendai virus and coronavirus 439 infection of Malayan pangolins (Manis javanica). Viruses 11, 979; 10.3390/v11110979 440 (2019).

26. Challender, D. et al. Manis javanica. The IUCN Red List of Threatened Species 2019: e.T12763A123584856; 10.2305/IUCN.UK.2019-3.RLTS.T12763A123584856.en. (2019).

27. Sikes, R.S., Gannon W.L., and the animal care and use committee of the American Society of Mammalogists. Guidelines of the American Society of Mammalogists for the use of wild mammals in research. J. Mammal. 92, 235-253; 10.1644/10-MAMM-F-355.1 (2011).

28. Hassanin, A. et al. Pattern and timing of diversification of Cetartiodactyla (Mammalia, Laurasiatheria), as revealed by a comprehensive analysis of mitochondrial genomes. C.R. biol. 
29. Tu, V.T. et al. Integrative taxonomy of the Rhinolophus macrotis complex (Chiroptera, 450 Rhinolophidae) in Vietnam and nearby regions. J. Zool. Syst. Evol. Res. 55, 177-198; 451 $\begin{array}{ll}10.1111 / \text { jzs. } 12169 \text { (2017). } & 452\end{array}$

30. Larsson, A. AliView: a fast and lightweight alignment viewer and editor for large data sets. 453 Bioinformatics 30, 3276-3278; 10.1093/bioinformatics/btu531 (2014). 454

31. Hijmans, R.J., Cameron, S.E., Parra, J.L., Jones, P.G. \& Jarvis, A. Very high resolution 455 interpolated climate surfaces for global land areas. Int. J. Climatol. 25, 1965-1978; 456 $\begin{array}{ll}\text { 10.1002/joc.1276 (2005). } & 457\end{array}$

32. Kuhn, M. Building predictive models in R using the caret package. J. Stat. Softw. 28, 1-26; 458 $\begin{array}{ll}\text { 10.18637/jss.v028.i05 (2008). } & 459\end{array}$

33. Dormann, C.F. et al. Collinearity: a review of methods to deal with it and a simulation study 460 evaluating their performance. Ecography 36, 27-46; 10.1111/j.1600-0587.2012.07348.x 461 (2013). $\quad 462$

34. Warren, D.L. et al. ENMTools 1.0: an $\mathrm{R}$ package for comparative ecological 463 biogeography. Ecography 44, 504-511; 10.1111/ecog.05485 (2021). 464

35. Wisz, M.S. et al. Effects of sample size on the performance of species distribution models. 465 Divers. Distrib. 14, 763-773; 10.1111/j.1472-4642.2008.00482.x (2008). 466

36. Fielding, A.H. \& Bell, J.F. A review of methods for the assessment of prediction errors in 467 conservation presence/absence models. Environ. Conserv. 24, 38-49; 468 10.1017/S0376892997000088 (1997). 469

37. Raes, N. \& ter Steege, H. A null-model for significance testing of presence-only species 470 distribution models. Ecography 30, 727-736; 10.1111/j.2007.0906-7590.05041.x (2007). $\quad 471$ 
In Cambodia, we would like to acknowledge T.D. Vong, V. Hul and S. In for their support during

Denis for their assistance. The field mission was organized by UNESCO under the permissions of the National Authority for Preah Vihear, the President, His Excellency Mr. Chuch Phoeurn and the Director of the Preah Vihear temple, Prof. Hang Soth. In Laos, we would like to thank N. Beevang, organized by the UNESCO and « La Maison du Patrimoine » (World Heritage House) of Luang Prabang, and the Phongsaly Forest Conservation and Rural Development Project, a Lao-European cooperation. Survey permission and authorization for tissue samples collecting were granted by the Ministry of Agriculture and Forestry, Department of Livestock and Fisheries. In Vietnam, we would like to acknowledge P.D. Tien (IEBR), D.Q. Thang and N.X. Nghia (Ngoc Linh NR) and N.T. Son (Vu Quang NP) for their support during the field surveys. We are grateful to L.X. Canh, T.H. Thai, N.V. Sinh and other colleagues of the IEBR, Hanoi for administrative assistance. The field research was done under the permissions of the People's Committees of numerous provinces and the Vietnamese Ministry of Agriculture and Rural Development (Vietnam Administration of Forestry). The fieldwork was also supported by the "Société des Amis du Muséum et du Jardin des 
A.H. wrote the main manuscript text; V.T.T. and A.H. sequenced the CO1 barcodes; V.T.T. and 503 A.H. prepared table S1; A.H. prepared figures 1, 2, 3, and 6, and table S2; M.C. and A.H. prepared 504 figures 4, 5, and S1-S3; A.H, G.C., and V.T.T. collected bats in different localities of Southeast 505 Asia. All authors reviewed the manuscript.

Competing interests

The author(s) declare no competing interests.

Data Availability: DNA sequences generated for this study were deposited in the GenBank 511 database (accession numbers MW712891-MW713034).

Ethical statement: Ethical review and approval were not available for our study because the field missions were carried out between 2004 and 2011, i.e., before the creation of the ethical committee at the Muséum national d'Histoire naturelle. However, the field studies were carried out in 


\section{Figures}

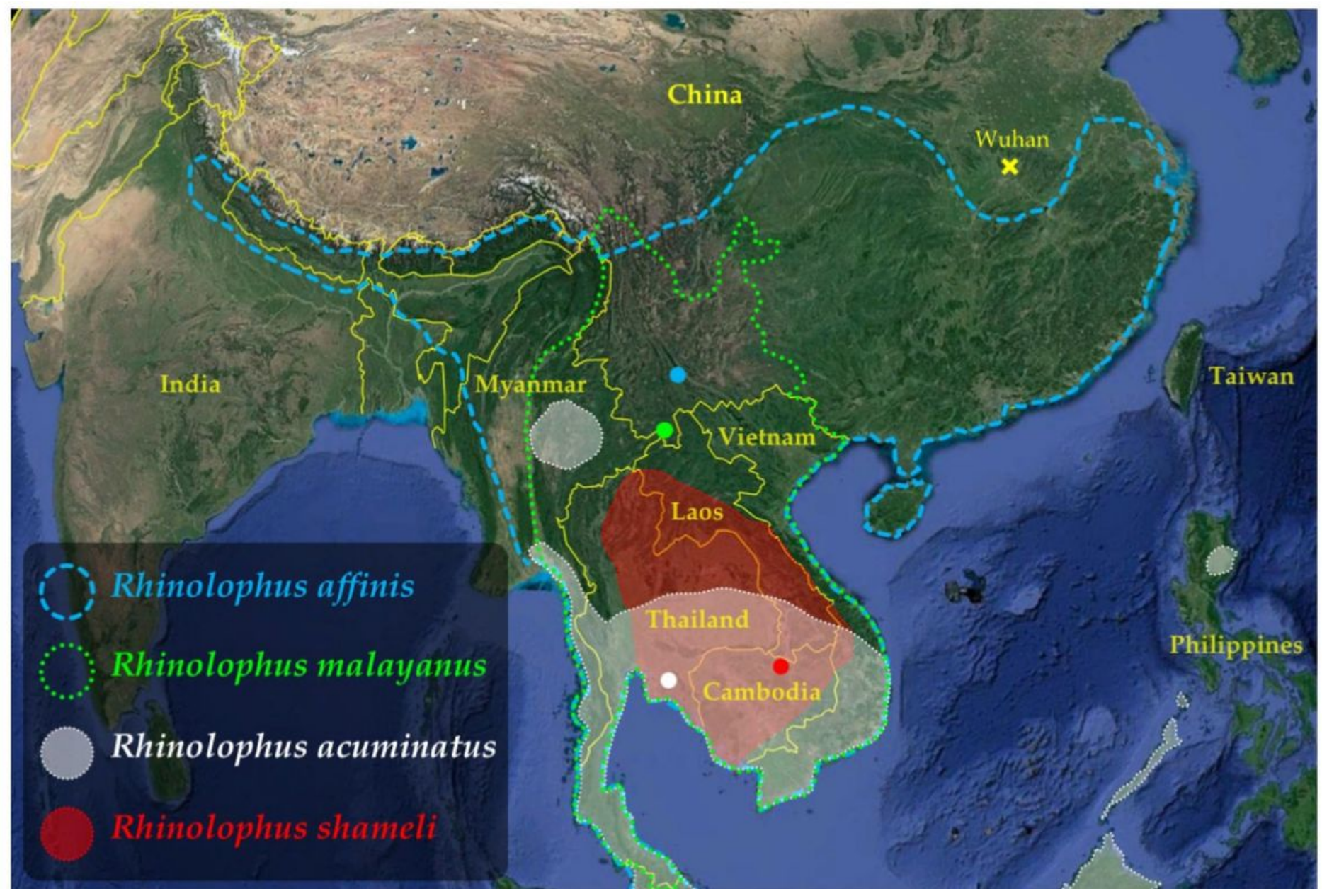

\section{Figure 1}

Geographic distribution of the four Rhinolophus species found positive for viruses closely related to SARS-CoV-2 in southern China and Southeast Asia. Map from Google Earth US Dept of State Geographer (C) 2020 Google - Image Landsat / Copernicus - Data SIO, NOAA, U.S. Navy, NGA, GEBCO. For each of the four Rhinolophus species, the geographic distribution was extracted from the IUCN website [11]. The coloured dots show the four geographic locations where bats found positive for SCoV2rCs were collected Note: The designations employed and the presentation of the material on this map do not imply the expression of any opinion whatsoever on the part of Research Square concerning the legal status of any country, territory, city or area or of its authorities, or concerning the delimitation of its frontiers or boundaries. This map has been provided by the authors. 


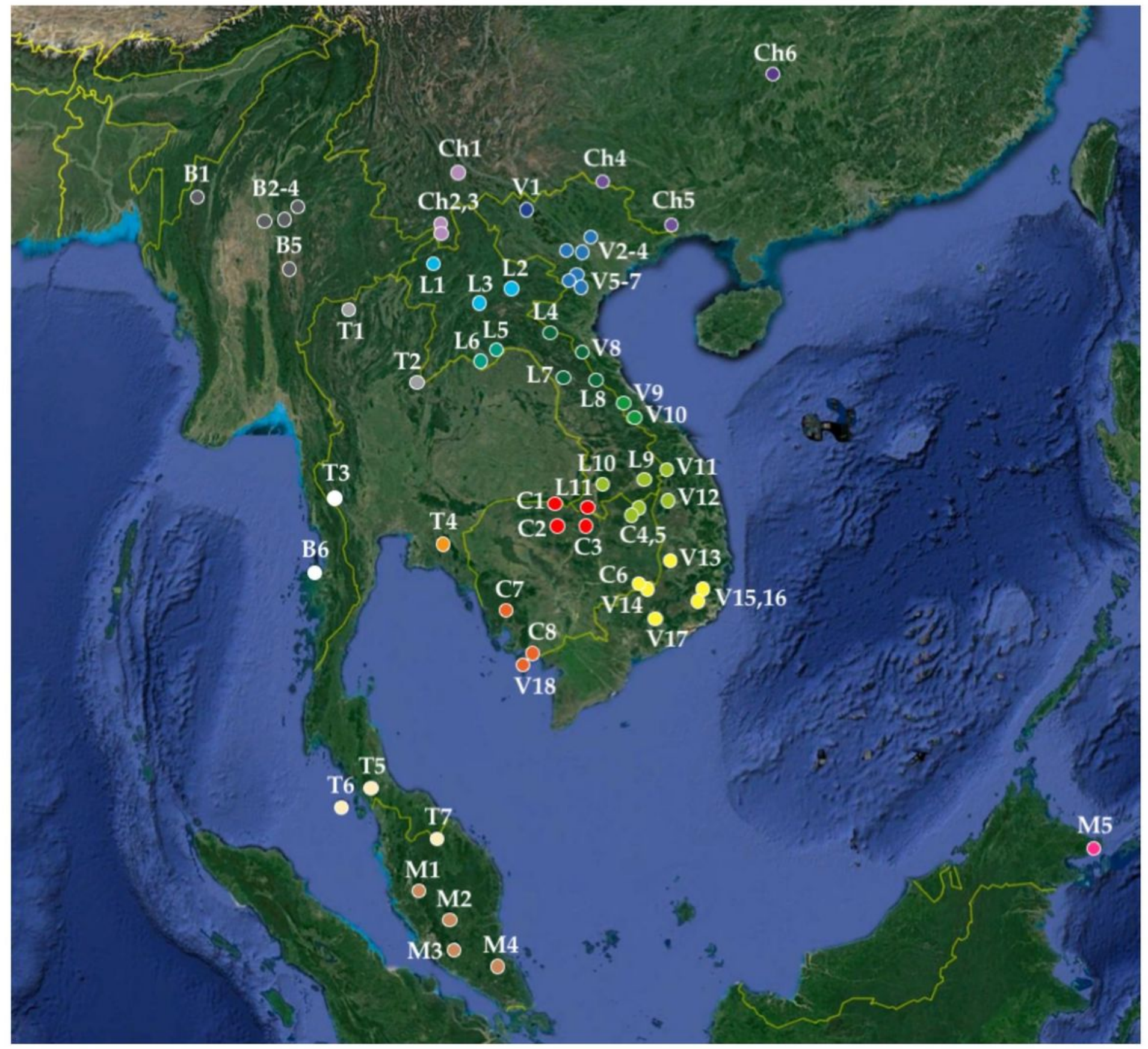

\section{Figure 2}

Geographic localities analysed in this study. The codes used for the countries are the following: B (Myanmar), C (Cambodia), Ch (China), I (Indonesia), L (Laos), M (Malaysia), T (Thailand), and V (Vietnam). Different regions were highlighted using colours. Map from Google Earth US Dept of State Geographer @ 2020 Google - Image Landsat / Copernicus - Data SIO, NOAA, U.S. Navy, NGA, GEBCO. The locality names and GPS coordinates are provided in online supplementary table S1 Note: The designations employed and the presentation of the material on this map do not imply the expression of any opinion whatsoever on the part of Research Square concerning the legal status of any country, territory, city or area or of its authorities, or concerning the delimitation of its frontiers or boundaries. This map has been provided by the authors. 


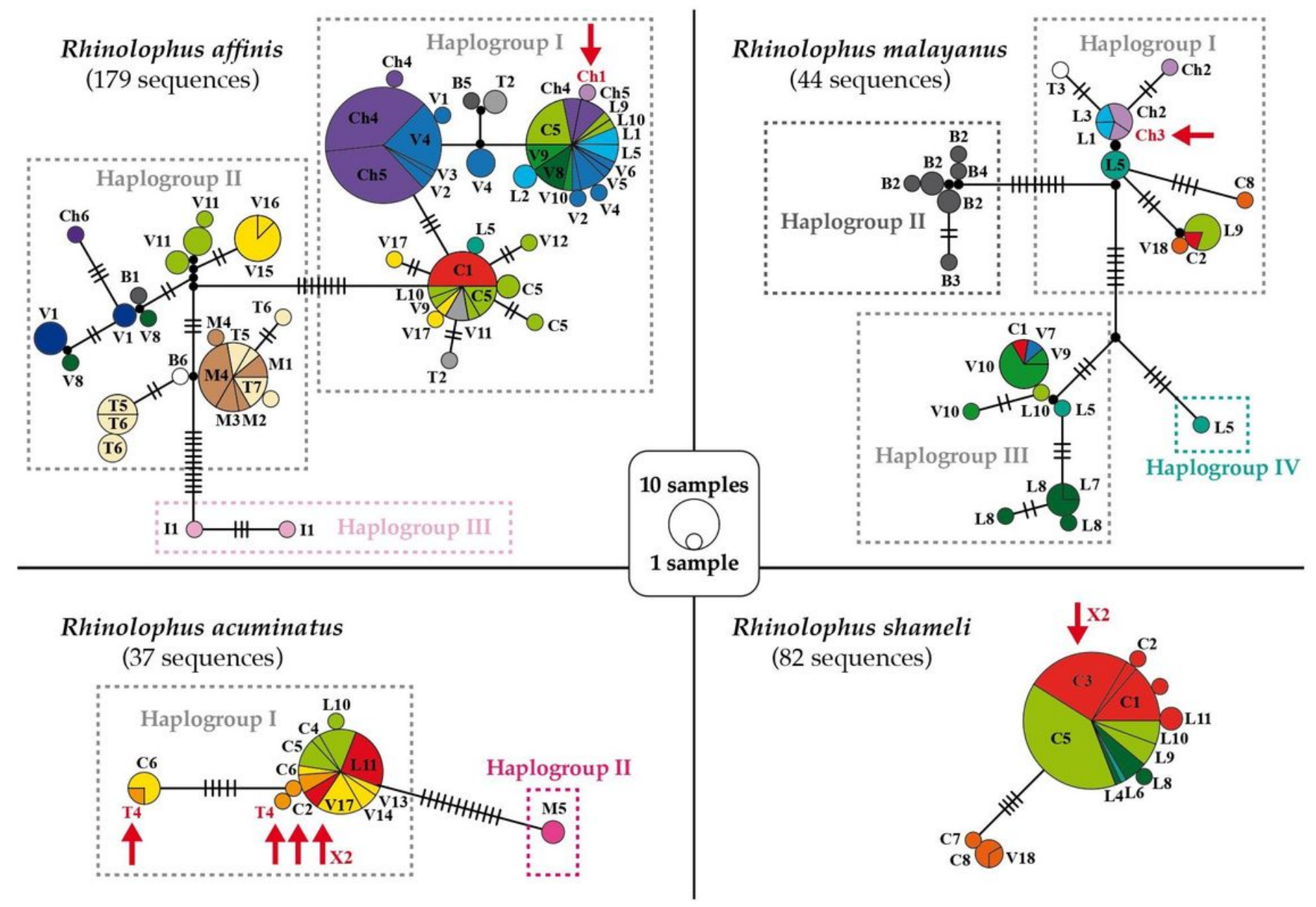

Figure 3

Haplotype networks based on $\mathrm{CO} 1$ sequences of the four Rhinolophus species found positive for viruses closely related to SARS-CoV-2 (SCoV2rCs). The networks were constructed with the median joining method available in PopART 1.5 [13]. The codes used for the countries are the following: B (Myanmar), C (Cambodia), Ch (China), I (Indonesia), L (Laos), M (Malaysia), T (Thailand), and V (Vietnam). Colours indicate the geographic origin of haplotypes according to Fig. 2 (see online supplementary table S1). The circles indicate haplotypes separated by at least one mutation. The black lines on the branches show the number of mutations $\geq 2$. Black circles represent missing haplotypes. Circle size is proportional to the number of haplotypes. Haplogroups separated by more than seven mutations (pairwise nucleotide distances $>1 \%$ ) are highlighted by dotted lines. The red arrows show the positions of the nine bats found positive for SCoV2rCs. 


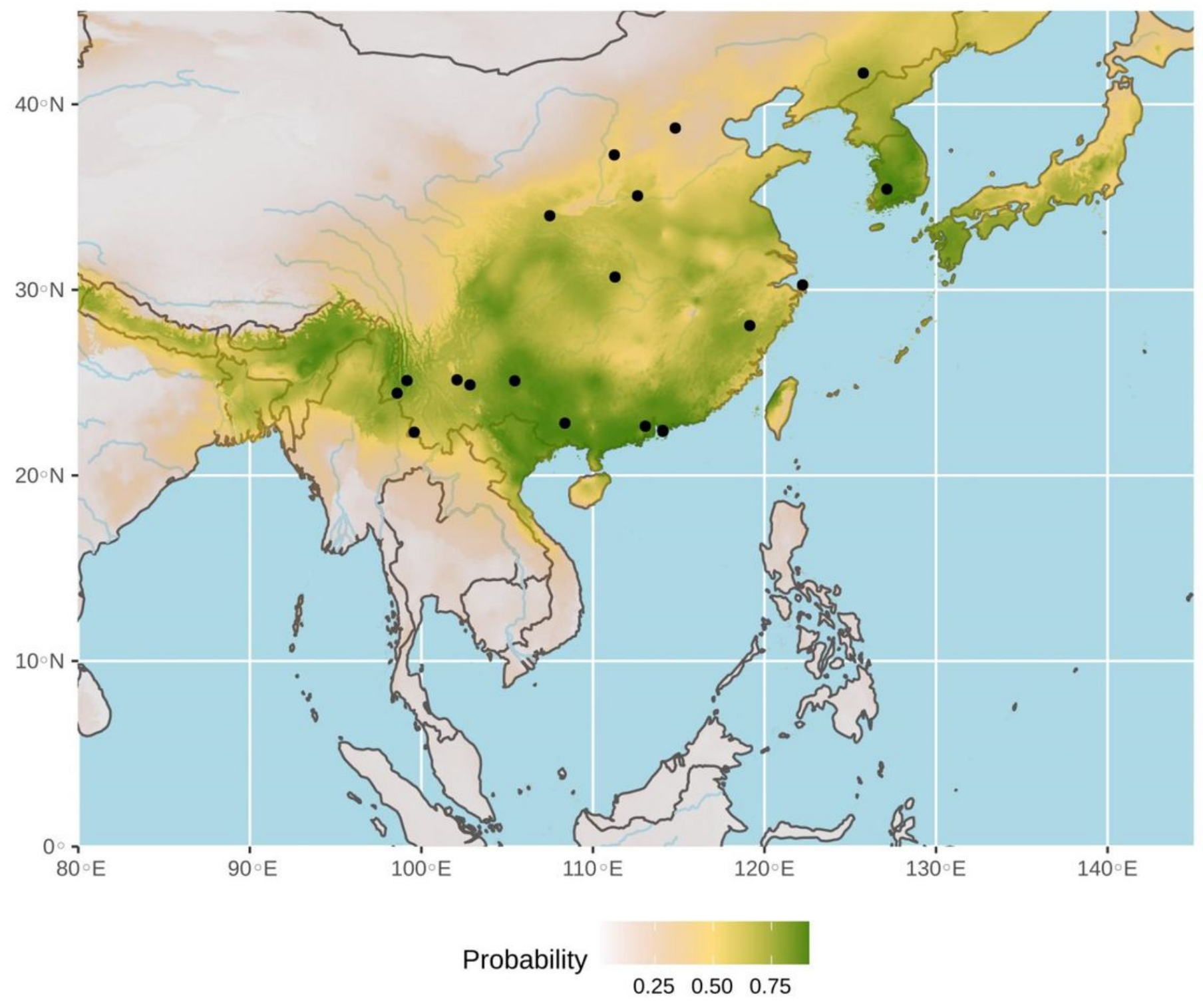

\section{Figure 4}

Ecological niche of bat viruses related to SARS-CoV (SCoVrCs). The geographic distribution of suitable environments was predicted using the Maxent algorithm in ENMTools (see Methods for details). AUC = 0.81. Black circles indicate localities used to build the distribution model (see geographic coordinates in online supplementary table S2). Note: The designations employed and the presentation of the material on this map do not imply the expression of any opinion whatsoever on the part of Research Square concerning the legal status of any country, territory, city or area or of its authorities, or concerning the delimitation of its frontiers or boundaries. This map has been provided by the authors. 

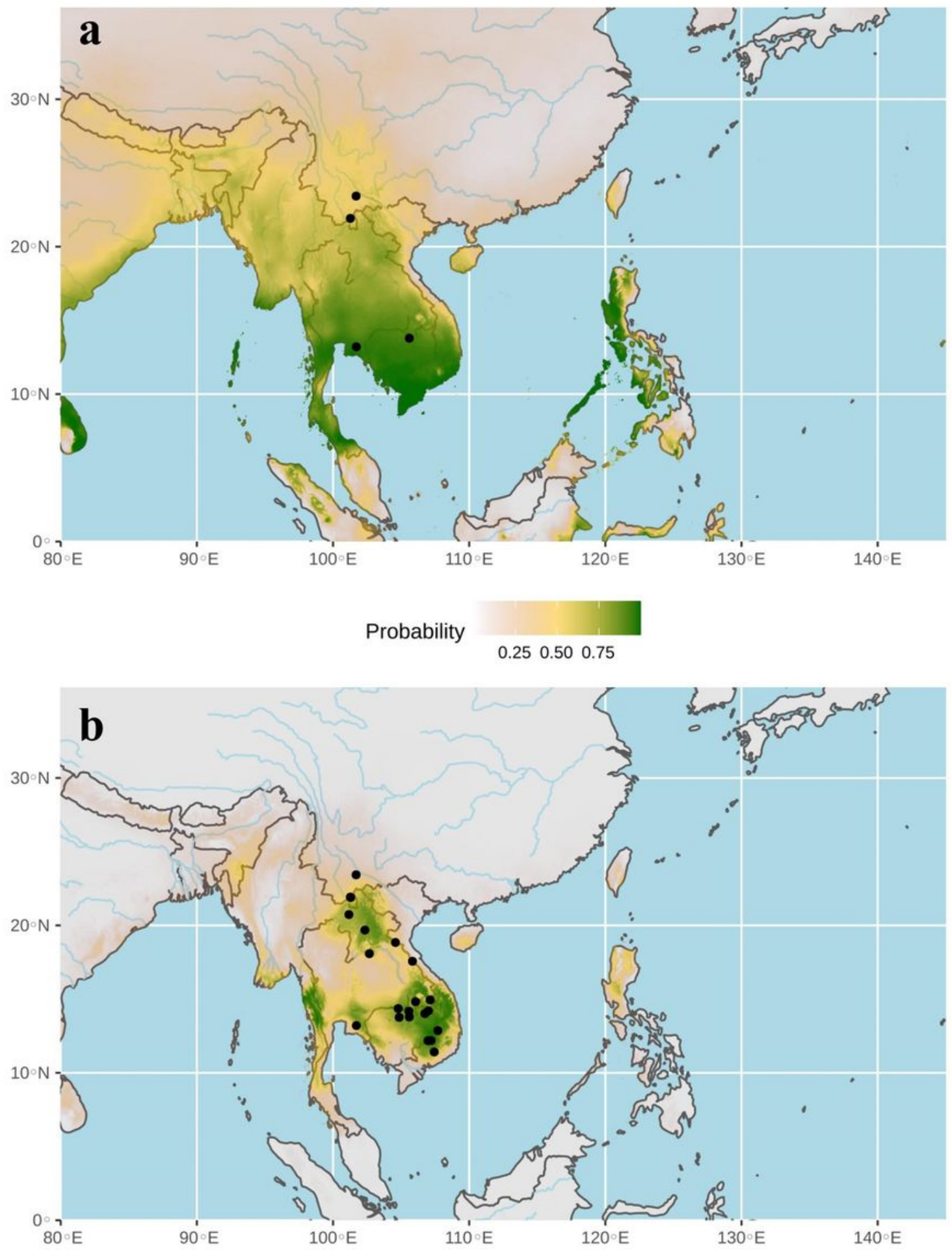

\section{Figure 5}

Ecological niches of bat viruses closely related to SARS-CoV-2 (SCoV2rCs) predicted using 4 points (a) $(A U C=0.58)$ and 21 points $(b)(A U C=0.96)$. The geographic distributions of suitable environments were predicted using the Maxent algorithm in ENMTools (see Methods for details). Black circles indicate localities used to build the distribution model (see geographic coordinates in online supplementary table S1). Note: The designations employed and the presentation of the material on this map do not imply the 
expression of any opinion whatsoever on the part of Research Square concerning the legal status of any country, territory, city or area or of its authorities, or concerning the delimitation of its frontiers or boundaries. This map has been provided by the authors.

\section{Cases / million}
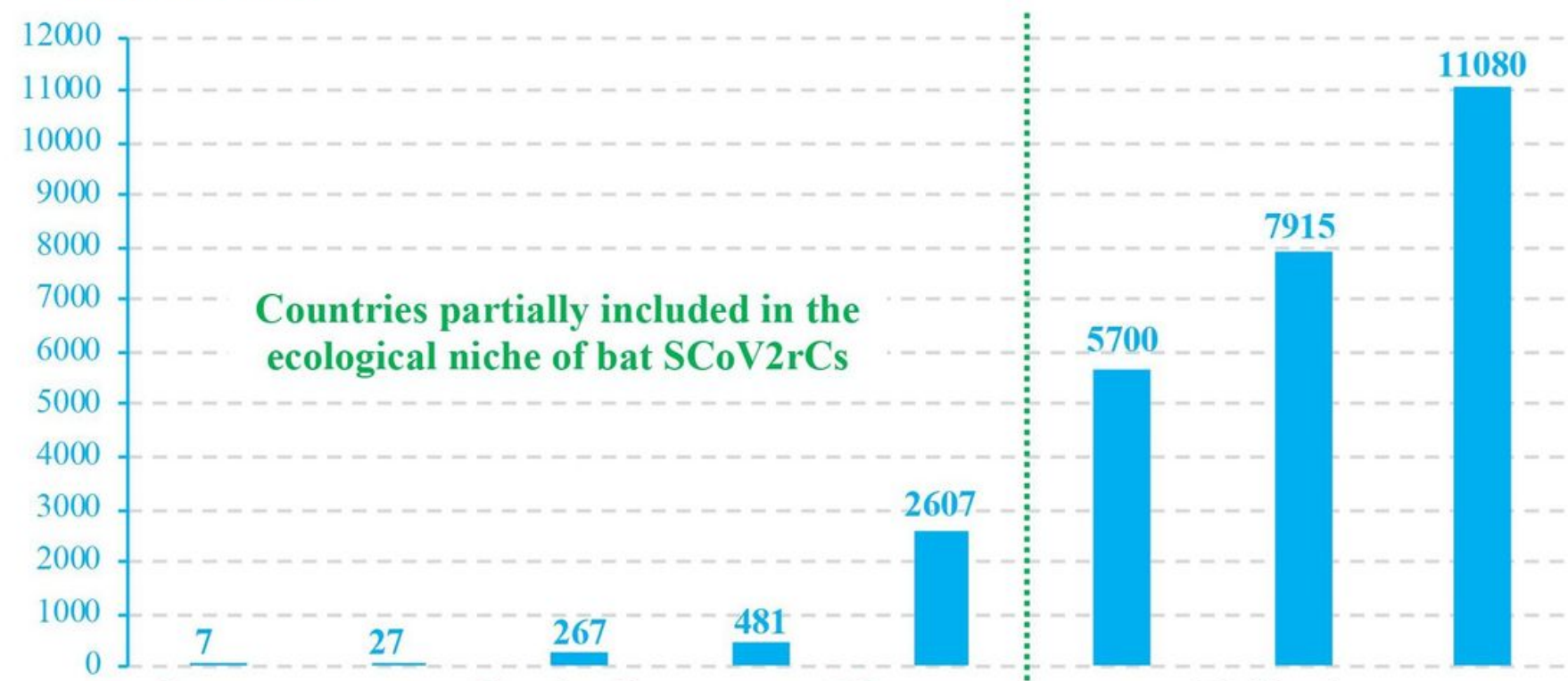

Laos

Cambodia

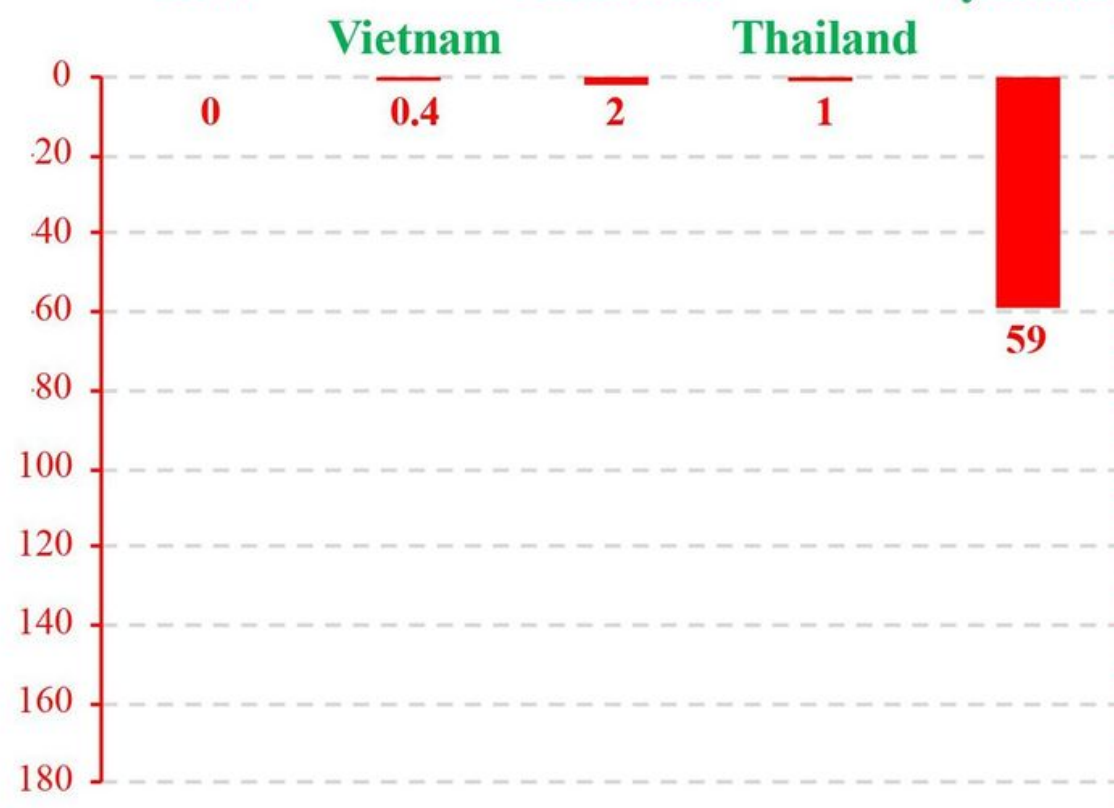

\section{Philippines}

Indonesia

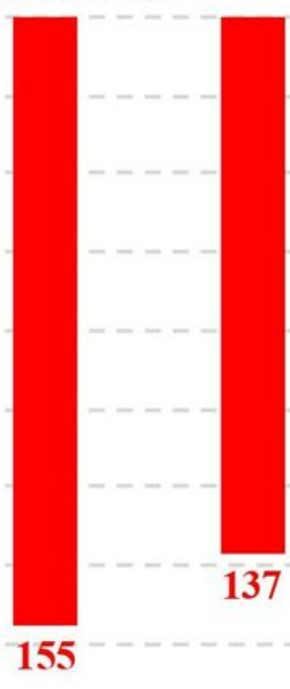

Malaysia

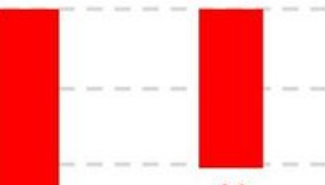

41

Deaths / million

\section{Figure 6}

Number of Covid-19 patients per million inhabitants (in blue) and deaths per million inhabitants (in red) for the different countries of Southeast Asia. Data extracted from the Worldometers website [2] on April 12,2021

\section{Supplementary Files}


This is a list of supplementary files associated with this preprint. Click to download.

- Supplementarylnformation.pdf 